\title{
RECORTES HISTÓRICOS DA MEDICALIZAÇÃO E A IMPLEMENTAÇÃO DO FÓRUM SOBRE A MEDICALIZAÇÃO DA EDUCAÇÃO E DA SOCIEDADE EM JATAÍ
}

\author{
Letícia Mendes Paiva-UFG/RJ \\ Thassia Silva Carrijo-UFG/RJ \\ Joice Veridiane Schumacher-UFG/RJ \\ Tiago Cassoli-UFG/RJ
}

Resumo: O presente texto é fruto do projeto de extensão universitária "Fórum sobre a Medicalização da Educação e da Sociedade/Jataí/GO" e tem como objetivo principal, apresentar e problematizar os processos de medicalização e medicamentalização da sociedade e, para tanto, realizamos alguns recortes históricos sobre tais processos e seus efeitos. Posteriormente apresentamos o processo de implementação do Fórum Sobre a Medicalização da Educação e da Sociedade no município de Jataí/GO e finalizamos com a análise da banalização de algumas práticas de diagnóstico na educação hoje. Temos como resultado o mapeamento de algumas alianças que constituem o poder médico-psiquiátrico, dentre elas, a aliança com a psicanálise, a biologia e a neurociência. Concluímos que a medicalização na educação decorre de práticas e procedimentos disciplinares presentes na sociedade que almejam homogeneizar as diferenças entres as pessoas e, consequentemente, medicar aqueles que fogem aos padrões estabelecidos pela norma médica e psiquiátrica. Essa normalização das condutas ocorre por meio de psicofármacos, cujo uso busca gerir os riscos sociais das consideradas más condutas, assumindo, muitas vezes, uma nova forma de punição.

Palavras-chave: Medicalização, psiquiatria, história e sociedade

Historical reviews of medicalization and implementation of the Forum about Medicalization of Education and Society in the city of Jataí/GO

Abstract: The present work is a result of the university extension program "Forum about Medicalization of Education and Society in the city of Jataí/GO" that have as its main objective, showcase and argue about the process of medicalization and medication of society, for that purpose, we made some historical reviews about such processes and their effect. Posterior to these reviews we present the process of implementation of the Forum About Medicalization in Education and Society in the city of Jataí/GO and analyze some trivialized practices of diagnoses in today's education. We have as a result the mapping of some alliances that constitute the medic and psychiatric power, among them, the alliance with psychoanalysis, biology and neuroscience. We conclude that medicalization in education is a result of practices and proceedings in society that aims to homogenize the difference between people and, hence, medicate those that are not in tune with the established medic and psychiatric standards. This normalization of human conduct is possible because of psychotropic medications, which aim is to lessen the social risk of bad conducts but, embodies, many times, a new form of punishment. 
Keywords: Medicalization, psychiatry, history, society

\section{Introdução}

O presente texto é fruto do projeto de extensão universitária "Fórum sobre a Medicalização da Educação e da Sociedade/Jataí/GO” e tem como objetivo principal, apresentar e problematizar os processos de medicalização e medicamentalização da sociedade e, para tanto, realizamos alguns recortes históricos sobre tais processos e seus efeitos. Posteriormente apresentamos o processo de implementação do Fórum Sobre a Medicalização da Educação e da Sociedade no município de Jataí/GO e finalizamos com a análise da banalização de algumas práticas de diagnóstico na educação hoje. Temos como resultado o mapeamento de algumas alianças que constituem o poder médico-psiquiátrico, dentre elas, a aliança com a psicanálise, a biologia e a neurociência. Finalizamos com a problematização de algumas práticas de diagnóstico na educação hoje como o teste SNAP-IV e papel de professores e psicólogos frente aos procedimentos da medicalização.

Para a realização deste estudo utilizamos as seguintes fontes: livros, artigos, relatórios com a temática da Saúde Mental, Educação, Medicalização, TDAH, em diversos bancos de dados: Scientific Electronic Library Online (Scielo), Google Scholar, e Periódicos Eletrônicos em Psicologia (PePSIC), no período entre 1999 e 2016. Buscamos analisar estes discursos relacionando estes às práticas de diagnósticos.

Segundo Foucault (2005), a partir do século XVIII o mundo ocidental conhece uma intensa transformação nos mecanismos de poder; o poder de soberania caracterizado pela possibilidade de causar a morte ou de deixar viver - personificado no rei - é substituído agora, por um poder técnico que tem por objetivo fazer viver, e fazer viver no sentido mesmo de produção da vida, tanto do ponto de vista orgânico quanto ético, moral, estético, ou seja, um poder que incide na produção das condutas, a partir de normas, práticas de controle e disciplinares, práticas confessionais, dos saberes jurídicos, médicos, psiquiátricos e psicológicos, econômicos, pedagógicos, etc.

O processo de medicalização da sociedade começa no século XVIII quando o corpo do indivíduo, assim como sua vida e das populações começam a se tornar alvos de estratégias políticas, como é o caso da entrada dos fenômenos, experiências, condutas, enfim, condições próprias da vida humana. Como exemplo disso temos os índices de natalidade, morbidade, fecundidade entre outros, assim como leis que funcionam como normas na constituição do estado moderno. A vida se torna objeto da medicina e do poder médico com o processo de 


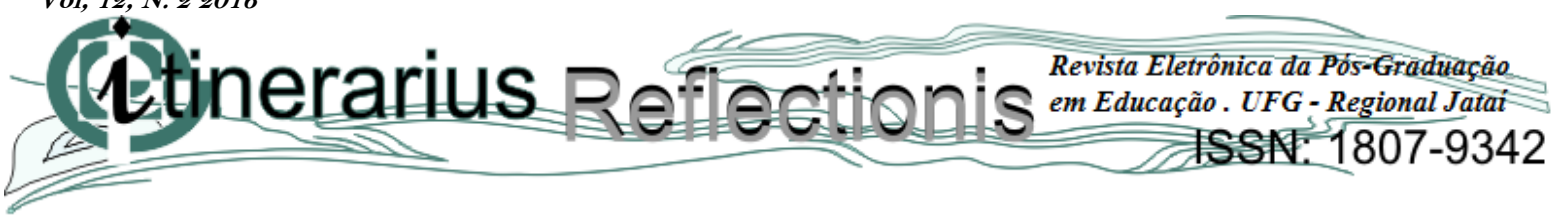

constituição do Estado Moderno, que começou a ser levada em consideração por mecanismos estatais de saber e de poder que tem por fim estabelecer controle sobre ela e a modificá-la, melhorá-la (FOUCAULT, 2001).

E, em "Vontade de Saber", Foucault (2001) apresenta o conceito de Biopoder por oposição ao direito de morte que caracterizava o poder do soberano ${ }^{1}$. Para Dreyfus \& Rabinow (1995)

\begin{abstract}
seria necessário falar de Biopoder para designar aquilo que faz entrar a vida e seus mecanismos no domínio dos cálculos explícitos e faz do poder-saber um agente de transformação da vida humana (...) o homem moderno é um animal em cuja política de sua vida, enquanto ser vivo, está em questão (DREYFUS \& RABINOW,1995, p. 148).
\end{abstract}

É por se ocupar da vida, mais do que das iminências da morte, que o poder produz os processos biológicos para estabelecer controle sobre eles e modificá-los. Foucault (2005) define essa nova tecnologia de poder como aquela que está incumbida de estabelecer uma espécie de regulamentação sobre a vida. O termo é usado por ele para designar o que faz com que a vida e seus mecanismos entrem no domínio dos cálculos explícitos, e faz do poder-saber um agente de transformação da vida humana (FOUCAULT, 1999).

Posteriormente, Foucault apresenta o conceito de biopolítica que corresponde ao governo da vida das populações, entendendo-a como espécie. Foucault (2005) ao falar da biopolítica diz que:

\footnotetext{
(...) a nova tecnologia que se instala se dirige a multiplicidade dos homens, não na medida em que ela forma, ao contrário, uma massa global, afetada por processos de conjunto que são próprios da vida, que são processos como o nascimento, a morte, a produção, a doente, etc. Logo depois de uma primeira tomada de poder sobre o corpo que se faz consoante o modo da individualização, temos uma segunda tomada de poder que por sua vez, não é individualizante mas é massificante, se vocês quiserem, que se faz em direção não do homem-corpo, mas do homem-espécie. Depois da anátomo-política do corpo humano, instaurada no decorrer do século XVIII, vemos aparecer, no fim do mesmo século, algo que já não é uma anátomopolítica do corpo humano, mas que eu chamaria de uma 'biopolítica' da espécie humana (p. 289).
}

\footnotetext{
${ }^{1}$ Foucault opõe e deixa de lado dois sistemas de análise do poder: O poder como repressão e o poder como soberania. Este último sistema, que encontramos nos filósofos do século XVIII, articula-se em torno do poder concebido como um direito originário que se cede e ao contrato como fonte de poder político (CASTRO, 2009).
} 
Fala-se de biopolítica pois os novos objetos de saber que se criam são destinados ao controle da própria espécie; a população é o novo conceito construído para dar conta de uma dimensão coletiva que até esse momento não havia sido uma questão no campo dos saberes (DANNER, 2010). A biopolítica trabalha então com a população como uma questão não apenas política como também científica, biológica e de poder. A população é o novo corpo a ser controlado, um corpo de múltiplas cabeças, e para abranger e conhecer melhor esse corpo se torna necessário não apenas descrevê-lo, mas também quantificá-lo. Além disso, é fundamental saber utilizar essas descrições e quantificações para geração de diversos saberes (FOUCAULT, 2005).

A biopolítica vai se ocupar dos processos relacionados ao homem-espécie, estabelecendo sobre esses uma condição de regulamentação (DANNER, 2010). Como tecnologia de poder que vai gerir e controlar as multiplicidades humanas, ela possui vários mecanismos que a ajudam a realizar essa tarefa. Estes são mecanismos de controle, que vão normalizar os corpos com o objetivo final de controle da população, se tratando sobretudo de:

\footnotetext{
Estabelecer mecanismos reguladores que, numa população global com seu campo aleatório, vão poder fixar um equilíbrio, manter uma média, estabelecer uma espécie de homeostase, assegurar compensações, em suma, instalar mecanismos de previdência em torno desse aleatório que é inerente a uma população de seres vivos, de otimizar, se vocês preferirem um estado de vida (FOUCAULT, 2005, p.293).
}

Umas das implicações práticas desse tipo de poder, que é encarregado de promover a vida, é o estabelecimento da norma. A norma não se define como uma lei natura, mas pela sua função de legitimar e justificar práticas de punição, disciplinares e de controle das populações (FOUCAULT, 2010). A norma pode ser tanto aquilo que se pode aplicar a um corpo que se quer disciplinar, como aquilo que se pode aplicar a uma população para a regulamentar (DANNER, 2010).

O sentido da norma é existir algo fora dela que não correspondesse a sua exigência, logo, normalizar seria conferir uma exigência a uma existência. A partir desse parâmetro, a norma é sempre individual, isto é, ela não indica uma média, mas sim uma noção de limite que delimita o máximo da competência de um ser (CANGUILHEM, 2000).

O processo de medicalização é então uma estratégia da biopolítica, ao passo que se utiliza de meios de normalização e processos de normatização da vida, que não são meios de simplesmente punitivos, mas constituintes da própria vida dos indivíduos, e assim, existe toda uma tecnologia do comportamento humano ligada a eles (IGNÁCIO; NARDI, 2007). Sendo 
uma estratégia da biopolítica, a medicalização vai compartilhar da sua dupla função de controlar os corpos da mesma forma que controla a população.

Historicamente, o processo de medicalização apareceu atrelado ao modelo de saber científico, como auxiliar no tratamento da doença, portanto, este tinha como função ajudar a afirmar a clínica nosográfica - através da medicalização o paciente se torna objetivado por meio de um saber que se constitui como verdade, neste caso, o saber da medicina; então, tendo como base essa objetificação, a medicalização atua como normalizadora da vida. Como um dispositivo biopolítico a medicalização aparece na modernidade ligada aos programas de higienização que eram realizados na Europa entre os séculos XVII e XVIII, aparecendo como uma medida de saneamento coletivo, que tinha como fim banir as pestes, tratar as doenças, etc. (FOUCAULT, 2001).

A sociedade brasileira de uma forma geral vive um processo de medicalização de todas as esferas da vida. Entende-se por medicalização o processo de objetivação da vida, seu bios, assim como suas condutas pelo saber médico e psiquiátrico, enfim questões não médicas tornam-se, nos dias de hoje, em problemas médicos e, portanto, alvos de suas intervenções e procedimentos.

Dificuldades de diferentes âmbitos são tomadas como "doenças", "transtornos", "distúrbios", que acabam por encobrir questões sociais, políticas, culturais, afetivas que afligem a vida das pessoas. Questões que são coletivas são tomadas como sendo individuais, problemas sociais e políticos vão se tornar biológicos, a responsabilidade recai sobre o indivíduo, enquanto governos, autoridades, profissionais são "livrados" de suas responsabilidades (GRUPO DE TRABALHO EDUCAÇÃO E SAÚDE DO FÓRUM SOBRE A MEDICALIZAÇÃO DA EDUCAÇÃO E SAÚDE, 2015). Há um processo de individualização do processo político em que o indivíduo surge como único culpado de seu fracasso social, ou intelectual, emocional, e é nesse contexto que o remédio nasce com uma função tática normalizadora de condutas consideradas desviantes.

\subsection{Os processos de medicamentalização}

Atualmente, a sociedade produz a medicalização e a psiquiatrização da vida, ambos os processos se distinguem, mas se apoiam reciprocamente. A medicalização é um processo mais amplo e antigo, que torna a vida um objeto exclusivo da medicina, cabendo a ela produzir saberes e práticas que buscam enquadrar a vida a partir da racionalidade médica. Já a 
psiquiatrização institui processos de normalização e normatização das condutas humanas (FOUCAULT, 2010). Dessa forma, a medicalização e a psiquiatrização produzem práticas medicamentosas que tendem em seus objetivos medicamentalizar problemas cotidianos, como insônia, tristeza e envelhecimento, com a promessa de que as pílulas são capazes de abdicar o ser humano de todo sofrimento, criando a necessidade de ser medicalizado (WANNMACHER, 2007). Vale ressaltar que o processo de medicamentalização está diretamente relacionado à indústria farmacêutica, uma das mais lucrativas do mundo.

O medicamento, tido como produto precioso legitimado por um aparato tecnológico, começa a ser produzido como a solução de problemas relacionados aos governos das condutas. Este desdobramento do processo de medicalização da sociedade chama-se de medicamentalização, que é o uso de remédios com fins de correção de condutas consideradas desviantes. Não é mais necessário localizar uma origem patológica para os sintomas, basta conferir a sua distância com relação a um padrão considerado normal para que seja prescrito um tratamento baseado nos novos medicamentos dispostos no mercado. Os remédios se prestam à resolução de toda e qualquer disfunção ou inadequação orgânica, psíquica ou comportamental; não se pretende mais a cura, mas a normatização, a padronização dos indivíduos (DANTAS, 2009).

Pode ser dito que os processos de medicamentalização causam uma troca de lugares: “ao invés de se fabricarem remédios para as doenças, fabricam-se doenças para os remédios, com vistas ao aquecimento de um mercado que se abre para a indústria farmacêutica com a criação de supostas doenças" (GRUPO DE TRABALHO EDUCAÇÃO E SAÚDE DO FÓRUM SOBRE A MEDICALIZAÇÃO DA EDUCAÇÃO E SAÚDE, 2015, p.11). A relação entre a indústria farmacêutica e os estudos que comprovam a eficácia dos seus produtos está muito distante de ser considerada como uma relação ética. A relação entre a produção de processos de medicamentalização da sociedade e indústria farmacêutica é evidente nos discursos médicos e psicológicos que acabam produzindo demandas de medicamentos através do aumento do número de diagnósticos.

Diante da fomentação acerca da medicamentalização psiquiátrica da sociedade, estão fatores como a produção utilitarista a respeito do sofrimento humano, ao mesmo tempo em que ocorre o acelerado avanço das descobertas das neurociências e dos métodos diagnósticos atuais, estes que estão diretamente ligados à indústria farmacêutica e à mídia de tal modo que se fortalecem e se alimentam de forma mútua. Logo, estes ditos "físiologismos", são 
responsáveis por emitir produtos a serem consumidos (ALVARENGA; FRANCISCATTI, 2011).

Nessa direção, a educação não se encontra fora deste processo de medicalização, ao contrário, as variadas dificuldades dos processos educativos, muitas vezes aumentadas por um sistema educacional com problemas, são prontamente reduzidas a possíveis diagnósticos que vão trazer uma sensação de alívio aos profissionais da escola assim como para os pais (GRUPO DE TRABALHO EDUCAÇÃO E SAÚDE DO FÓRUM SOBRE A MEDICALIZAÇÃO DA EDUCAÇÃO E SAÚDE, 2015). No texto "Funcionamentos escolares e a produção do fracasso escolar e sofrimento" Souza (2007), traz uma série de mecanismos que facilitam a introdução de práticas medicalizantes no contexto escolar, dentre elas é possível destacar a atitude de encaminhar aos especialistas os alunos que não correspondem ao padrão pré-estabelecido, essa prática deve ser problematizada, pois ela tende a atribuir ao indivíduo, no caso ao aluno, a responsabilidade por não estarem dentro de um padrão e assim reforçam os mecanismos de medicalização.

No Brasil, a crítica e o enfrentamento da questão e dos processos de medicalização e de medicamentalização se encontram ainda no princípio, neste contexto é constituído o Fórum sobre Medicalização da Educação e da Sociedade, o qual será exposto ao longo do presente estudo, bem como, o processo de implementação deste no município de Jataí/GO.

\section{Apresentação do Fórum sobre a medicalização da educação e da sociedade como movimento nacional}

O Fórum Sobre a Medicalização da Educação e da Sociedade está diretamente ligado à luta antimanicomial, uma vez que problematiza a normatização da saúde presente na atualidade, pela qual o indivíduo portador de um transtorno mental é culpabilizado, enquanto o governo e as políticas públicas isentam-se de suas responsabilidades, além de questionar o uso exacerbado de medicamentos na sociedade, que transforma questões não médicas em questões médicas e correspondem a interesses políticos e econômicos da indústria farmacêutica (FÓRUM SOBRE A MEDICALIZAÇÃO DA EDUCAÇÃO E DA SOCIEDADE, 2010).

O Fórum Sobre a Medicalização da Educação e da Sociedade, que foi iniciado entre os dias 11 e 13 de novembro de 2010, durante o I Seminário Internacional “A Educação 
Medicalizada: Dislexia, TDAH e outros supostos transtornos”, em São Paulo, se fundamenta nos seguintes princípios:

\author{
Contra os processos de medicalização da vida; \\ Defesa das pessoas que vivenciam processos de medicalização; \\ Defesa dos Direitos Humanos; \\ Defesa do Estatuto da Criança e Adolescente; \\ Direito à Educação pública, gratuita, democrática, laica, de qualidade e socialmente \\ referenciada para todas e todos; \\ Direito à Saúde e defesa do Sistema Único de Saúde (SUS) e seus princípios; \\ Respeito à diversidade e à singularidade, em especial, nos processos de \\ aprendizagem; \\ Valorização da compreensão do fenômeno medicalização em abordagem \\ interdisciplinar; \\ Valorização da participação popular (FÓRUM SOBRE A MEDICALIZAÇÃO DA \\ EDUCAÇÃO E DA SOCIEDADE, 2010).
}

Atualmente o Fórum sobre a Medicalização da Educação e da Sociedade conta com diversas entidades signatárias que assinaram o manifesto distribuído por todo país, entidades essas que buscam levar às suas regiões a discussão traga pelo Fórum, podendo assim ampliar o alcance do tema tendo em vista sua relevância.

Deste modo, o Fórum traz como desafios, a ampliação à democratização do debate; busca por estabelecimento de mecanismos de interlocução com a sociedade civil; popularização do debate; pluralização dos meios de divulgação; estabelecimento de mecanismos interlocutores com a academia; ampliação da discussão entre profissionais das diversas áreas, construção de crítica que desnaturalize essas práticas medicalizante, dentre outras.

\title{
2.1 Apresentação do Fórum em Jataí e da Pesquisa-Intervenção a partir da perspectiva da análise institucional
}

O Fórum Sobre a Medicalização da Educação e da Sociedade foi apresentado às estudantes do curso de Psicologia da Universidade Federal de Goiás/Regional Jataí pelo docente Tiago Cassoli através do Estágio Curricular Obrigatório Básico em Psicologia Social da Universidade Federal de Goiás/Regional Jataí no $2^{\circ}$ semestre de 2014, e foi aberto a outros discentes que se interessassem pela temática. Inicialmente foram desenvolvidas palestras com convidados que, de alguma forma, tivessem relação com a medicalização. Com o início do $1^{\circ}$ semestre de 2015 e o fim do estágio básico, o docente responsável pelo mesmo sugeriu às participantes que o Fórum Sobre a Medicalização da Educação e da Sociedade fosse 
transformado em Projeto de Extensão e então se inserisse nas instituições da Rede de Saúde Mental do Município de Jataí e a Rede de Escolas Estaduais e Municipais e desenvolvesse ações nas mesmas.

Buscamos nestes estabelecimentos desnaturalizar as verdades psiquiátricas entendidas como verdades que produzem as condutas humanas e relacionam essas condutas ao uso de psicotrópicos. Temos como problema de pesquisa os processos de normalização/normatização na sociedade. Utilizamos neste trabalho de ferramentas teóricas e metodológicas como a Pesquisa-Intervenção na perspectiva da Análise Institucional, além de historicizar os procedimentos médicos e psiquiátricos e seus saberes pela perspectiva foucaultiana. O público alvo são professores, alunos, profissionais da saúde e psicólogos.

O Projeto de Extensão Fórum sobre a Medicalização da educação e da sociedade de Jataí entende que é necessário a criação de espaços, eventos, que promovam o debate público a respeito das práticas de medicalização e medicamentalização da educação e da sociedade em estabelecimentos públicos e privados em Jataí e região, pois entende-se que estes podem funcionar como canais de comunicação e integração entre a universidade e a sociedade. Nesse sentido, entende-se que este projeto pode colaborar na criação de espaços que problematizem a verdade médica e psiquiátrica além de criar condições de produção de conhecimento entre universidade e comunidade. Entende-se, neste sentido, como fundamental aos processos de produção desconhecimento e de uma formação crítica da sociedade, a realização de atividades que intensifiquem os espaços de debate, estudos, culturais, incluindo a pesquisa e a extensão de forma transdisciplinar, integrando deste modo, alunos, professores, pesquisadores e profissionais de outros campos de saber com a comunidade regional.

$\mathrm{Na}$ intenção de criar e intensificar um processo de formação de profissionais dentro dos estabelecimentos públicos e privados de Jataí e região, a partir de parcerias entre diferentes campos de formação e a comunidade local, intenta-se problematizar a especialidade médica, as fragmentações do seu conhecimento, a privatização e comercialização de procedimentos e produtos relacionados ao corpo e a saúde. Enfim, a proposta para este empreendimento é questionar os discursos sobre a vida, os corpos, em diferentes níveis institucionais, como a saúde, a doença, a loucura, e tentarmos para isso criar espaços de debate com a população local, com os indivíduos que estão nos estabelecimentos, organizações, independente das hierarquias ou classes sociais. Problemas relacionados aos saberes que incidem em suas vidas: os conceitos que nos atravessam e ditam a nossa verdade. 
Buscamos elencar os analisadores que questionam certo modo de se relacionar consigo mesmo, com os outros, com a vida, produzidos nas relações de poder dos diversos domínios da psiquiatria.

Temos como base teórica e metodológica nestas intervenções a Análise Institucional a partir de Lapassade (1977) e Lourau (1995). Entendemos, assim, que a instituição não se confunde com o estabelecimento. O estabelecimento ou grupos de estabelecimentos constituem o nível da organização que se definem como conjuntos prático-concreto organizado para determinado fim. A Instituição é um conceito que explica o modo pelo qual se reproduzem, no seio das organizações de grupos, as formas das relações sociais predominantes na sociedade. Como tal, está presente ou atravessa todos os níveis de uma determinada formação social.

O conceito de instituição implica na análise dos processos de institucionalização. Este processo supõe sempre uma relação de oposição entre forças instituintes versus forças instituídas. O instituído não se impõe como um dado exterior aos homens, mas se conserva como tal por um processo ativo de manutenção que permanentemente se opõe às novas forças institucionais.

Entra em questão o processo de naturalização e desnaturalização das instituições. Processo tal constituído a partir do entendimento de que os objetos e sujeitos são dados a serem conhecidos, ou seja, dados a priori no processo de análise, a serem conhecidos por sua natureza. O questionamento de conceitos entendidos num a priori propõem então uma desconstrução da noção de essência para um deslocamento do próprio entendimento de sujeito. Ao não se perguntar sobre a proveniência dos objetos, ao tomá-los como objetos-paraele, o homem naturaliza tudo ao seu redor e passa a perseguir caminhos que, acredita, o levarão ao começo de tudo (BARROS, 2007).

Enfim, a Análise Institucional vai interrogar o próprio ato de instituir que constitui e define a instituição como natureza e que dá sentido às organizações enquanto mecanismos que as instrumentalizam ou as operacionalizam.

No trabalho que será proposto é o grupo que faz a análise, é ele que decompõe as instituições a partir da análise das implicações. É no grupo, portanto, no entre grupos, que propomos pensar as instituições que nos atravessam tomando, já de início, a discussão de ferramentas metodológicas que possam ajudar a questionar os processos de naturalização versus desnaturalização do sujeito. 
Pesquisa-intervenção, nesta linha de trabalho é uma proposta que vem para subverter, desestabilizar essa oposição tradicional que distinguiria entre o pensar e o fazer, entre aqueles que estão na labuta do corpo e aqueles considerados intelectuais. Ou seja, as velhas oposições teoria x prática e os correlatos outros dessa oposição, sujeito x objeto, estariam então submetidos a um foco crítico dos institucionalistas.

A intervenção estará associada à construção e/ou utilização de analisadores, conceitoferramenta formulado por Guattari. Os analisadores seriam acontecimentos, no sentido daquilo que produz rupturas, que catalisa fluxos, que produz análise, que decompõe (LOURAU, 1995).

Além disto, as ferramentas propostas no âmbito da Análise Institucional, como de implicação, pesquisa-intervenção contribuem sobremaneira para essa concepção de trabalho. A pesquisa intervenção surge como procedimento de aproximação com o campo e mostra-nos que ambos, pesquisador e pesquisado, ou seja, sujeito e objeto do conhecimento, constituemse no mesmo momento, no mesmo processo.

Dentre as organizações abarcadas pelo Fórum Sobre a Medicalização em seu início estão o CAPS - Centro de Assistência Psicossocial, o Ambulatório de Saúde Mental e o Centro de Convivência. Atualmente, acabamos de estabelecer uma parceria com a Subsecretaria de Jataí, em que realizaremos rodas de conversa com professores e pais, além da exibição de alguns filmes nas escolas.

No ano de 2014 deu-se início aos Encontros do Fórum na cidade de Jataí-GO, neste ano os eventos eram realizados dentro do espaço da Universidade Federal de Goiás/Regional Jataí, e contava com a participação de graduandos e docentes dos cursos de Psicologia, Direito, Pedagogia e Letras.

Os temas iniciais eram pré-estabelecidos (como por exemplo, a psicofarmacologia, a patologização da educação, luta antimanicomial, a saúde mental no município de Jataí, dentre outros), mas no decorrer da discussão os analisadores iam surgindo.

No I Encontro, houve a apresentação do tema geral e a exibição do documentário: O Marketing da Loucura e mesa redonda com dois professores do curso de Psicologia, enquanto no II Encontro houve a exibição dos vídeos: Nau dos insensatos - medicalização, Crianças (Porta dos fundos) e Debate com uma docente do curso de pedagogia. E o III Encontro contou com a exposição de três trabalhos de conclusão de curso de acadêmicas do curso de Psicologia cujos temas versavam sobre a discussão que o fórum traz. 
O primeiro Fórum do ano de 2015 contou com a exibição do filme "Passageiros de segunda classe" que subsidiou uma discussão bastante rica acerca do tratamento dos indivíduos nos antigos manicômios, e do quanto esta realidade esteve próxima. O segundo encontro do Fórum neste ano contou com a participação de uma profissional bastante importante na história da saúde mental em Jataí, no qual se debateu a respeito da história da Saúde Mental no município de Jataí. No terceiro encontro do ano foi realizada uma discussão acerca da psicofarmacologia, mediada por uma farmacêutica, bem como o relato de caso de uma pessoa que utilizou diversos medicamentos e foi internada em hospitais psiquiátricos, trazendo à tona uma realidade cruel ainda presente em nossa sociedade. $\mathrm{O}$ quarto e último encontro do ano de 2015 possuía o tema "Despatologização da educação", quando uma professora de psicologia escolar da Regional Jataí, problematizou a questão da medicalização infantil cada vez mais precoce em nossa sociedade.

Os eventos realizados no ambiente acadêmico visam possibilitar a construção de uma visão crítica dos graduandos, tanto dos períodos iniciais, quanto àqueles que já se encontram em processo de formação, sobre temáticas que são normatizadas pela medicina e pela psiquiatria e pelos interesses econômicos da indústria farmacêutica. As discussões promovidas proporcionam reflexões acerca do que deve ser criticado, e como se deverá agir da próxima vez em que se deparar com situações discutidas.

Além das atividades supracitadas, o Fórum começou a organizar cines debates. A ideia foi de promover discussões acerca da temática da medicalização através da exibição de filmes, que possibilitem o desenvolvimento crítico dos participantes. O projeto foi voltado para os discentes de Psicologia da Regional Jataí/GO, e os filmes eram exibidos nas instalações da clínica escola do curso. No ano de 2015, foram realizados dois eventos com esta perspectiva. No primeiro evento o filme foi "A guerra está declarada". E no segundo exibiu-se "Tarja branca".

\section{Medicalização da Educação e o crescente diagnóstico de TDAH}

Para finalizar este artigo, propomos trazer para o debate a medicalização na educação, que no contemporâneo, que patologiza as diferenças entres os alunos em suas práticas cotidianas, buscamos aqui questionar o crescente diagnóstico TDAH.

Nesse sentido, a indisciplina começa a ser compreendida como problema do indivíduo, e assim como as queixas e dificuldades escolares, vem a se tornar um problema médico, e 


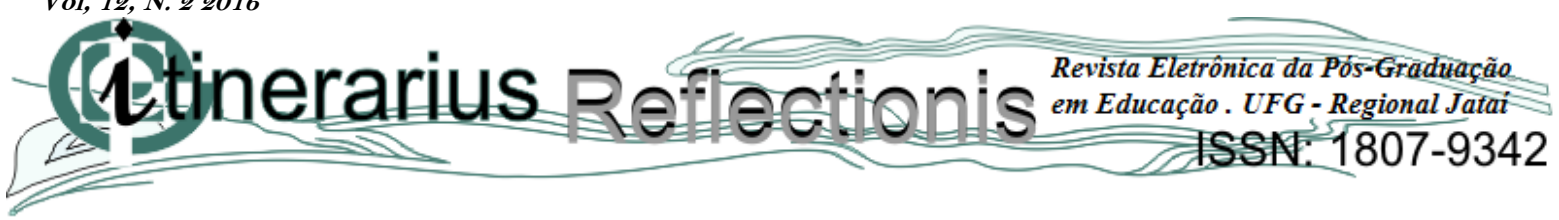

mais uma vez o aluno é diagnosticado e medicalizado (LEMOS; CRUZ; SOUZA, 2014), fato diretamente relacionado ao grande aumento de casos de Transtorno de Déficit de Atenção e Hiperatividade (MEIRA, 2012).

O Transtorno de Déficit de Atenção e Hiperatividade (TDAH) é descrito, pelo Manual de Diagnóstico e Estatística de Transtornos Mentais DSM-V - V Edição, da Associação Americana de Psiquiatria (2014), da seguinte forma:

A característica essencial do transtorno de déficit de atenção/hiperatividade é um padrão persistente de desatenção e/ou hiperatividade-impulsividade que interfere no funcionamento ou no desenvolvimento. A desatenção manifesta-se comportamentalmente no TDAH como divagação em tarefas, falta de persistência, dificuldade de manter o foco e desorganização - e não constitui consequência de desafio ou falta de compreensão. A hiperatividade refere-se à atividade motora excessiva (como uma criança que corre por tudo) quando não apropriado ou remexer, batucar ou conversar em excesso. Nos adultos, a hiperatividade pode se manifestar como inquietude extrema ou esgotamento dos outros com sua atividade. A impulsividade refere-se a ações precipitadas que ocorrem no momento sem premeditação e com elevado potencial para dano à pessoa (p. ex., atravessar uma rua sem olhar). A impulsividade pode ser reflexo de um desejo de recompensas imediatas ou de incapacidade de postergar a gratificação. Comportamentos impulsivos podem se manifestar com intromissão social (p. ex., interromper os outros em excesso) e/ou tomada de decisões importantes sem considerações acerca das consequências no longo prazo (p. ex., assumir um emprego sem informações adequadas) (p. 102).

Os referidos sintomas são avaliados através do questionário conhecido como SNAPIV - o qual será abordado adiante -, que pode ser encontrado no site da Associação Brasileira de Déficit de Atenção (ABDA). No presente site também é possível encontrar a informação de que o TDAH é um transtorno neurobiológico que se apresenta na infância e geralmente se mantem por toda a vida.

Este procedimento produz um grande reducionismo biomédico dos problemas da escola e dos processos de ensino-aprendizagem, uma vez que irão limitar-se somente aos aspectos neurobiológicos e comportamentais, e assim, o contexto histórico, social, filosófico e didático são silenciados. Esse reducionismo também é efetivado por docentes, que, através de suas relações de poder com o aluno, perpetuam a concepção de que as expressões da 
singularidade dos mesmos sejam entendidas como psicopatologias. Portanto, as subjetividades são moduladas por meio de psicofármacos, para que os riscos sociais sejam diminuídos no cotidiano das escolas e demais estabelecimentos de educação (LEMOS; CRUZ; SOUZA, 2014).

\subsection{Questionário SNAP-IV}

O questionário denominado SNAP-IV foi desenvolvido baseando-se nos sintomas de TDAH presentes no Manual de Diagnóstico e Estatística de Transtornos Mental - IV Edição (DSM-IV) da Associação Americana de Psiquiatria, o qual foi traduzido e validado pelo GEDA - Grupo de Estudos do Déficit de Atenção da Universidade Federal do Rio de Janeiro (UFRJ) e pelo Serviço de Psiquiatria da Infância e da Adolescência da Universidade Federal do Rio Grande do Sul (UFRGS), e visa facilitar a identificação de sintomas de TDAH em alunos (ASSOCIAÇÃO BRASILEIRA DO DÉFICIT DE ATENÇÃO, 2016).

Trata-se de um questionário, com os seguintes itens, que devem ser avaliados de acordo com a coluna que melhor descreve o aluno ("Nem um pouco", "Só um pouco", "Bastante", "Demais"):

1-não consegue prestar muita atenção a detalhes ou comete erros por descuido nos trabalhos da escola ou tarefas; 2-tem dificuldade de manter a atenção em tarefas ou atividades de lazer; 3-parece não estar ouvindo quando se fala diretamente com ele; 4-não segue instruções até o fim e não termina deveres de escola, tarefas ou obrigações; 5-tem dificuldade para organizar tarefas e atividades; 6-evita, não gosta ou se envolve contra a vontade em tarefas que exigem esforço mental prolongado; 7 perde coisas necessárias para atividades (p. ex: brinquedos, deveres da escola, lápis ou livros); 8-distrai-se com estímulos externos; 9-é esquecido em atividades do dia a dia; 10-mexe com as mãos ou os pés ou se remexe na cadeira; 11-sai do lugar na sala de aula ou em outras situações em que se espera que fique sentado; 12-corre de um lado para outro ou sobe demais nas coisas em situações em que isto é inapropriado; 13-tem dificuldade em brincar ou envolver-se em atividades de lazer de forma calma; 14-não pára ou frequentemente está a "mil por hora"; 15-fala em excesso; 16responde às perguntas de forma precipitada antes de elas terem sido terminadas; 17 tem dificuldade de esperar sua vez; 18-interrompe os outros ou se intromete (p.ex. mete-se nas conversas/jogos) (ASSOCIAÇÃO BRASILEIRA DO DÉFICIT DE ATENÇÃO, 2016). 
Tal formulário pode ser preenchido por professores ou médicos, porém, é comum que professores o façam e posteriormente encaminhem aos psiquiatras/neurologistas. Após o seu preenchimento, de acordo com o a Associação Brasileira do Déficit de Atenção, o profissional da educação deve avaliar o resultado do teste, pois, as afirmações de 1 a 9 dizem respeito a sintomas de desatenção, caso tenha 6 ou mais itens assinalados como "Bastante" ou "Demais", e as afirmações de 10 a 18 dizem respeito a sintomas de hiperatividade e impulsividade, caso tenha 6 ou mais itens assinalados como "Bastante" ou "Demais". Ao final, o site ressalta que o questionário avalia somente um critério (critério $\mathrm{A}$ - sintomas citados) para o diagnóstico do TDAH, e informa os outros critérios a serem analisados, atividade exclusiva de médicos (psiquiatras e/ou neurologistas), que são:

Critério B: Alguns desses sintomas devem estar presentes antes dos 7 anos de idade; Critério C: Existem problemas causados pelos sintomas acima em pelo menos 2 contextos diferentes (por ex., na escola, no trabalho, na vida social e em casa); Critério D: Há problemas evidentes na vida escolar, social ou familiar por conta dos diplomas; Critério E: Se existe um outro problema (tal como depressão, deficiência mental, psicose, etc.), os sintomas não podem ser atribuídos exclusivamente a ele(ASSOCIAÇÃO BRASILEIRA DO DÉFICIT DE ATENÇÃO, 2016).

Por fim, é evidente que, tanto a definição do transtorno quanto os critérios que o determinam demonstram a necessidade de uma análise crítica das práticas que constituem os indivíduos, além da problematização desse olhar patologizante que medica crianças cada vez mais jovens (MEIRA, 2012).

Esse olhar diz respeito ao poder psiquiátrico, explanado por Foucault (2007), o qual irá qualificar experiências comuns humanas como doença mental, e no caso da infância, patologiza as crianças que se apresentam violentas, furiosas e agitadas, bem como, aquelas que são consideradas abatidas, preguiçosas ou quietas demais. O referido autor critica essa normatização da infância, uma vez que, os comportamentos supracitados dizem respeito a características de crianças saudáveis, e quando se apresentam, são de forma temporária (FOUCAULT, 2007).

Foucault (2007) ressalta ainda que, esse poder psiquiátrico é baseado em uma razão econômica, pois, quando a criança demonstra comportamentos não-desejados, a família, e a própria sociedade, dão ao médico o poder de diagnosticar e tratar a criança, ou seja, além de 
controlar e corrigir a loucura, a psiquiatria dita o que é normal ou não para a sociedade. Logo, é através deste recorte de crianças ditas anormais, que a psiquiatria começa a agir de forma disciplinadora, e assim, tudo que é anormal dentro do contexto escolar e/ou social, recebe o tratamento devido, e consequentemente, o poder psiquiátrico dissemina-se na sociedade (FOUCAULT, 2007).

Sendo assim, é indispensável que haja uma postura crítica frente a medicalização de crianças, pois o diagnóstico traz diversos efeitos a longo prazo, desde físicos, até psíquicos, criando rótulos que se instalam e dificultam a vida do indivíduo em suas relações interpessoais, gerando grande sofrimento ao mesmo (FIORE, 2005). Além disso, é necessário avaliar os danos que podem decorrer do uso exacerbado de medicamentos, visto que, na maioria dos casos de TDAH, o medicamento indicado é a Ritalina, nome comercial do metilfenidato, que é um psicoestimulante que se propõe a melhorar o desempenho cognitivo, mas apresenta resultados ainda não-conclusivos quanto aos seus mecanismos de ação e podem causar dependência física ou psíquica (TREBIEN, 2011).

Conclui-se que os procedimentos psiquiátricos respondem a uma lógica do controle das condutas e do lucro, pois existe uma irracionalidade nos diagnósticos psiquiátricos nas escolas, que gera excesso do uso de medicamentos, que necessita ser problematizada, afinal, qual é o objetivo da escola?

\section{Considerações finais}

Hoje, a produção do saber médico e psiquiátrico está relacionado à indústria farmacêutica e a produção de novos medicamentos. Referentes aos transtornos mentais, de acordo com os dados da Organização Mundial de Saúde (OMS) em 2013, os transtornos já atingem cerca de 700 milhões de pessoas em todo o mundo, isto representa $13 \%$ no total de doenças (BUENO, 2013).

Em se tratando do Brasil, há cerca de 5 milhões de pessoas diagnosticadas com algum tipo de transtorno mental, e 23 milhões de brasileiros necessitam de algum atendimento voltado para a saúde mental e a maior prevalência está relacionada a depressão e ansiedade (LOURENÇO,2010).

A indústria farmacêutica, em 2008, faturou 773 bilhões de dólares. Nos últimos anos a indústria psicofarmacêutica é a que possui maior número de usuários e lucros. Só no Brasil, existe mais de 32 mil rótulos de medicamentos, com variações de 12 mil substâncias (a OMS 


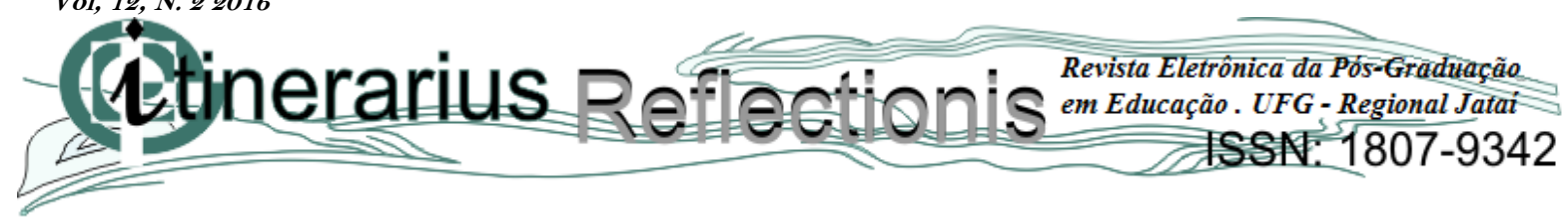

considera como realmente necessários 300 itens), vendidos em mais de 54 mil farmácias (uma para cada três mil habitantes, o dobro da recomendação da OMS) (CARNEIRO, 2011).

Além desta função econômica, constata-se ainda uma função política exercido pelo saber médico e psiquiátrico ao moralizar e normatizar as condutas humanas através das classificações patológicas existentes nos DSM's para em seguida medicalizar, com isso, o ato de medicalização é um procedimento de controle social que se sustenta na norma produzida por esses saberes.

Criam-se necessidades na população, diagnósticos, consultas, consumo de remédios, ao prometer a "cura" com o uso do medicamento. Desnaturalizar essa verdade foi nosso intuito ao relacioná-la aos interesses políticos e econômicos que estão por traz dos discursos normativos.

\section{Referências}

AMERICAN PSYCHIATNC ASSOCIATION. Manual de Diagnóstico e Estatístico de Transtornos Mentais. 3. ed. Porto Alegre: Artmed, 2014. v. 15, 948 p.

ASSOCIAÇÃO BRASILEIRA DO DÉFICIT DE ATENÇÃO (ABDA). Disponível em <http://www.tdah.org.br/br/sobre-tdah/diagnostico-criancas.html $>$. Acesso em: 10 mai. 2016.

BARROS, B. R. Grupo: a afirmação de um simulacro. Porto Alegre: Sulina /UFRGS, 2007.

BUENO, C. Transtornos mentais afetam 700 milhões no mundo; veja mitos e verdades. UOL, São Paulo, 2013. Disponível em: < noticias.uol.com.br/saude/ultimasnoticias/redacao/2013/11/11/transtornos-mentais-afetam-cerca-de-700-mi-no-mundo-vejamitos-e-verdades.htm\#fotoNav=1. >. Acesso em: 10 mai. 2016.

CANGUILHEM, G. O normal e o patológico (5. ed. rev. e aum.). Rio de Janeiro: Forense Universitária (Original publicado em 1943.), 2000.

CARNEIRO, H. Drogas: muito além da hipocrisia. 2011. Disponível em: < http://outraspalavras.net/posts/drogas-muito-alem-da-hipocrisia/ > . Acesso em: 27 mai. 2016.

DANNER, F. O sentido da biopolítica em Michel Foucault. Estudos Filosóficos, v.4, p. 143$157,2010$. 
DREYFUS, H.L; RABINOW, P. Michel Foucault, uma trajetória filosófica: para além do estruturalismo e da hermenêutica. Rio de Janeiro, RJ: Forense Universitária. 1995.

CASTRO, E. Vocabulário de Foucault - Um percurso pelos seus temas, conceitos e autores. Belo Horizonte: Autêntica Editora, 2009.

DANTAS, J. B. Tecnificação da vida: uma discussão sobre o discurso da medicalização da sociedade. Factral: Revista de Psicologia, v. 21, a. 3, p. 563-580, 2009.

FIORE, M. A. Medicalização do corpo na infância - Considerações acerca do Transtorno do Déficit de Atenção e Hiperatividade. Mnemosine. v. 1, n. 1, 2005.

FÓRUM SOBRE A MEDICALIZAÇÃO DA EDUCAÇÃO E DA SOCIEDADE. 2010. Disponível em: <http://medicalizacao.org.br/>. Acesso em: 19 de fev. 2016.

FOUCAULT, M. Direito de morte e poder sobre a vida. In M. Foucault (Ed.) História da Sexualidade 1: A Vontade de Saber. 13. ed., v. 1. Rio de Janeiro: Graal, 1999. p. 125- 149.

FOUCAULT, M. O nascimento da clínica. 5. ed. Rio de Janeiro: Forense Universitária, 2001.

FOUCAULT, M. Aula de 17 de marro de 1976. In: FOUCAULT, M. (Ed.). Em defesa da sociedade: Curso no Collège de France (1975-1976). 4. ed., v.1, São Paulo: Martins Fontes, 2005. p. 285- 316.

FOUCAULT, M. Clase del 16 de enero de 1974. In: FOUCAULT, M (Ed.). El poder psiquiátrico. Buenos Aires: Fondo de Cultura Económica, 2007. p. 229-264.

FOUCAULT, M. Os anormais. São Paulo: Martins Fontes. 2010.

IGNÁCIO, V. T. G.; NARDI, H.C. A medicalização como estratégia biopolítica: um estudo sobre o consumo de psicofármacos de um pequeno município do Rio Grande do Sul.

Psicologia e Sociedade, v. 19, n. 3, p. 88-95, 2007. 
medicalizantes para profissionais e serviços de educação e saúde. Conselho Federal de Psicologia, 2015.

LEMOS, F. C. S.; CRUZ, F. F.; SOUZA, G. S. Medicalização da produção da diferença e racismos em algumas práticas educativas pacificadoras. Revista Profissão Docente. Uberaba, v. 14, n. 30, p. 7-20, jan./jun., 2014.

LAPASSADE, G. Grupos, organizações e instituições. Rio de Janeiro: Francisco Alves, 1977.

LOURAU, R. A análise institucional. Petrópolis: Vozes, 1995.

LOURENÇO, L. Transtornos mentais atingem 23 milhões de pessoas no Brasil. Agência Brasil. 2010. Disponível em:

$<$ http://saude.ig.com.br/transtornos+mentais+atingem+23+milhoes+de+pessoas+no+brasil/n1 237686125917.html >. Acesso em: 12 abr. 2016.

MEIRA, M. E. M. Para uma crítica da medicalização na educação. Revista Semestral da Associação Brasileira de Psicologia Escolar e Educacional. v. 16, n. 1, p. 135-142, jan./jun., 2012.

SOUZA, B.P. Funcionamentos escolares e a produção do fracasso escolar e sofrimento. In: SOUZA, B. P. Orientação à queixa escolar. São Paulo: Casa do Psicólogo, 2007, p. 241278.

TREBIEN, H. A. et al. Medicamentos - Benefícios e Riscos com Ênfase na

Automedicação. 2011. 320 f. Tese de Mestrado - Universidade Federal do Paraná, Curitiba.

WANNMACHER, L. A ética do medicamento: múltiplos cenários. Uso racional de medicamentos: temas selecionados. Brasília, DF, v. 4, n. 8, p. 1-6, jul. 2007. 